\title{
Research Article \\ Effect of Different Templates on the Synthesis of Mesoporous Sodalite
}

\author{
Shima Shirani Lapari, ${ }^{1}$ Zainab Ramli, $^{1}$ and Sugeng Triwahyono ${ }^{2}$ \\ ${ }^{1}$ Department of Chemistry, Faculty of Science, Universiti Teknologi Malaysia (UTM), 81310 Johor Bahru, Johor, Malaysia \\ ${ }^{2}$ Ibnu Sina Institute for Fundamental Science Studies, Universiti Teknologi Malaysia (UTM), 81310 Johor Bahru, Johor, Malaysia \\ Correspondence should be addressed to Zainab Ramli; zainab@kimia.fs.utm.my
}

Received 11 March 2015; Accepted 31 May 2015

Academic Editor: Hongxun Hao

Copyright (c) 2015 Shima Shirani Lapari et al. This is an open access article distributed under the Creative Commons Attribution License, which permits unrestricted use, distribution, and reproduction in any medium, provided the original work is properly cited.

\begin{abstract}
Sodalite is a type of zeolite having ultramicropore size and high thermal stability with strong basic sites. However, sodalite has several drawbacks in the catalyst application due to its smallest pore size $(2.8 \AA)$ and low surface area. To overcome these disadvantages, microporous sodalite can be modified to have mesoporous structure but maintain its active sites suitable for catalyst applications. This study was focused on the synthesis of mesoporous sodalite using various organic templates as structure directing molecules. A hierarchical mesoporous sodalite has been synthesized hydrothermally at $150^{\circ} \mathrm{C}$ for crystallization by using several mesotemplate and fumed silica as a silica source. The synthesized samples were characterized using XRD, FTIR, BET surface area, and FESEM. XRD and FTIR showed that all templates being used in the synthesis produced sodalite phase. The sodalite synthesized using organosilane (trimethoxysilyl-propyldimethyloctadecyl ammonium chloride) and mixture of tetrapropyl ammonium hydroxide and cetyltrimethylammonium bromide with ratio of $1: 1$ showed mesoporosity as proven by higher BET surface area as compared to microporous sodalite with different pore structure as proven by pore distribution.
\end{abstract}

\section{Introduction}

Zeolites are microporous crystalline aluminosilicates, compositionally similar to clay minerals, but differing in their well-defined three-dimensional microporous structure. Aluminum, silicon, and oxygen are arranged in a regular structure of $\left[\mathrm{SiO}_{4}\right]^{-}$and $\left[\mathrm{AlO}_{4}\right]^{-}$tetrahedral units that form a framework with regular pores form of tunnels, channels, or cavities of about 0.1-2 $\mathrm{nm}$ diameter running through the material [1]. Zeolites have been used as ion-exchange and molecular sieves in the separation and removal of gases and solvents. In addition, zeolites have the ability to act as catalyst for chemical reactions which take place within the internal cavities [2]. An important class of reactions is that catalyzed by hydrogen-exchanged zeolites, whose framework-bound protons give rise to very high acidity. Due to this property, zeolites have been used as a catalyst in petrochemistry and fine-chemical industry because of their large surface area, high adsorption capacity, high thermal and hydrothermal stabilities, strong acid sites within their defined micropores, and their shape selectivity in catalysis [3].
In many catalytic applications, the main drawback of zeolites is their intricate pore and channel systems in the molecular size ranging from 0.3 to $1.5 \mathrm{~nm}$. Thus, large molecules cannot react effectively over these microporous materials because of the limitation of their small pore sizes [4]. To solve the diffusion problems of guest species in zeolites, mesoporous materials with adjustable larger pore sizes, such as MCM-41 and SBA-15, have been successively invented [5]. Mesoporous material, as defined by IUPAC nomenclature, is material with pore of free diameters in the range of $2-50 \mathrm{~nm}$ [6]. These materials can overcome the pore size constraint of microporous zeolites and allow the diffusion of lager molecules [7]. As compared with conventional zeolites, these mesoporous materials exhibited insufficient hydrothermal stability and acidity, which limits their use as catalysts in a wide range of industrial processes and reactions. In order to overcome the limitations of single micro- or mesoporous materials and to combine the advantages of these two types of molecular sieves, various attempts to synthesize mesoporous aluminosilicate materials 
with improved framework crystallinity have been devoted to synthesize nanosized zeolite with ultralarge pore zeolites and hierarchical mesoporous zeolite.

Up to date, zeolites with mesoporosity have been successfully synthesized such as ZSM-5 [2], zeolite Y [4], zeolite A [5], and zeolite X [6]. They pave a way to introducing mesopores into the zeolite crystals in recent years and thus have the advantages of both mesostructured materials (fast diffusion and accessible for bulky molecules) and microporous zeolite crystals (strong acidity and high hydrothermal stability). Mesoporous ZSM-5 and A zeolites were synthesized using an amphiphilic organosilicate as mesopore-directing agent [8]. Mesoporous ZSM-5 zeolite has also been prepared using a silylated polyethylenimine as mesopore-directing agent. Following these attempts, synthesizing of mesoporous zeolites has been widely investigated and the most used templates are polymers, long chain organosilicates, and amphiphilic surfactants [9]. For example, mesoporous ZSM-11 templated by polyvinyl butyral, mesoporous Y templated by long chain organosilicates [8], and mesoporous ZSM-5 templated by CTAB or F127 or P123 have been reported [10].

Sodalite (SOD) is type of zeolite having ultramicropore size and high thermal stability with strong basic sites. There have been very few attempts for the catalytic utilizations of ordinary microsized sodalite crystals because of their low surface area. However, recent studies have shown that sodalite has potential as a catalytic material [9]. Mesoporous sodalite with a surface area of around $190 \mathrm{~m}^{2} / \mathrm{g}$ and special properties including high aluminum content, high stability in basic solution, highly crystalline zeolitic walls, and high surface was successfully synthesized using amphiphilic organosilane surfactant as structure directing molecule [10]. It showed the possibility of modifying the ultramicropore zeolite such as sodalite to having high specific surface area and mesoporosity [11]. However, up to this date no other type of structure directing molecule beside amphiphilic organosilane has been reported in the formation of the mesoporous sodalite. Thus, this paper focused on finding other types of structure directing templates that can be used to form mesoporous sodalite.

\section{Methodology}

The hydrothermal synthesis of mesoporous sodalite was performed by preparing a sol containing oxide ratios of $1.7 \mathrm{SiO}_{2}: 15 \mathrm{Na}_{2} \mathrm{O}: 1 \mathrm{Al}_{2} \mathrm{O}_{3}: 80 \mathrm{H}_{2} \mathrm{O}: 0.3$ templates [10]. First, $\mathrm{NaOH}$ solution was prepared by dissolving $\mathrm{NaOH}$ pallet (Merck, EMSURE, >99\%) as alkali source in distilled water. The solution was divided into two portions equally. One portion of alkaline solution was mixed with fumed silica to form silicate mixture and the other portion was mixed with $\mathrm{NaAlO}_{2}$ (Riedel-de-Haën) as alumina source to form aluminate solution. Then, template was added to silicate solution. Both solutions were heated at $100^{\circ} \mathrm{C}$ to dissolve the solid until clear solutions formed. The solutions then were cooled down to RT. The silicate solution was then added dropwise into the aluminate solution. The solution formed was transferred into stainless steel autoclave and was heated at $150^{\circ} \mathrm{C}$ for $6-$ 24 hours. After separating the solid product obtained was washed using distilled water until the filtrate solution reached
$\mathrm{pH}$ 7. The recovered solid product was dried at $60^{\circ} \mathrm{C}$ for 24 hours, followed by calcination at $550^{\circ} \mathrm{C}$ for 6 hours to remove the organic templates. In this study, the templates that have been used were trimethoxsilylpropyldimethyloctadecyl ammonium chloride (organosilane), tetrapropyl ammonium hydroxide (TPA), cetyltrimethylammonium bromide (CTABr), and mixture of TPA : CTABr with mole ratio of $1: 1$. The synthesized samples obtained were SOD-OS for trimethoxysilyl-propyldimethyloctadecyl ammonium chloride (organosilane), SOD-TP for tetrapropyl ammonium hydroxide (TPA), SOD-CT for cetyltrimethylammonium bromide (CTABr), and SOD-TC for mixture of TPA : CTABr with mole ratio of $1: 1$.

Characterization of the synthesized samples was carried out by X-Ray Diffractometer (Model Bruker D8) with radiation source $\mathrm{Cu} K \alpha$ that has $\lambda=1.542 \AA$ at $40 \mathrm{kV}$ and current of $10 \mathrm{~mA}$. The sample was mounted into the sample holder and was scanned in the degree of $2 \theta$ at the range of $5-50^{\circ}$ with the step size of $0.05^{\circ}$ in order to confirm the formation of pure sodalite phase [12]. The crystallite size of the synthesized samples was calculated theoretically using Debye-Scherrer equation, while the crystallinity was calculated by taking the total intensity of 2 main peaks at angle $2 \theta$, around 13.97 and 24.938. In this study, crystallinity of sodalite sample without template was taken as $100 \%$ crystallinity. The crystallinity of other samples was compared to this sodalite sample.

The presence of tetrahedral $\mathrm{TO}_{4}(\mathrm{~T}=\mathrm{Si}$ or $\mathrm{Al})$ bonding and formation of zeolite was determined using Fourier Transform Infrared Spectroscopy (FTIR) [13]. The spectrum was elucidated for zeolite framework structure at wavenumbers between 400 and $1500 \mathrm{~cm}^{-1}$. The band positions of $\mathrm{TO}_{4}$ tetrahedral for zeolite framework are assigned according to the previous work [14].

The Brunauer-Emmett-Teller (BET) method was used to determine the specific surface area of samples [12]. The specific surface areas of materials were calculated from the adsorption branch of the isotherm using the BrunauerEmmett-Teller (BET) equation [15]. Pore size distribution was analyzed by using the Barrett-Joyner-Halenda (BJH) method. The surface area of the samples was conducted by Micromeritics 2010 V3.01G analyzer. An amount of $0.02-$ $0.03 \mathrm{~g}$ of the sample was weighed and heated at $300^{\circ} \mathrm{C}$ for 1 hour to dehydrate the sample. The sample was removed quickly to the sample station to the nitrogen adsorption analysis in which the analysis was fully done automatically by the instrument [16]. The surface area and pore distribution were obtained from the software of the instrument [17].

The morphology of samples was determined by using Field Emission Scanning Electron Microscopy. Samples were coated with Pt powder at 5.0 KV with 100.000 time magnification [18].

\section{Results and Discussion}

3.1. Sodalite Phase Formation. Figure 1 shows the XRD of the synthesized sample without template and samples using different types of organic structure directing molecules including organosilane, TPA, CTABr, and TPA : CTABr with mole ratio of $1: 1$. XRD phase of sodalite is found to match with the 
TABLE 1: The crystallite size and crystallinity of sodalite formed using different templates.

\begin{tabular}{lccc}
\hline Sample & Template & $\begin{array}{c}\text { Crystallite } \\
\text { size }(\mathrm{nm})\end{array}$ & $\begin{array}{c}\text { Crystallinity } \\
(\%)\end{array}$ \\
\hline SOD & - & 20 & $100^{*}$ \\
SOD-OS & Organosilane & 15 & 94 \\
SOD-CT & CTABr & 9 & 64 \\
SOD-TP & TPA & 11 & 42 \\
SOD-TC & TPA and CTABr $1: 1$ & 19 & 91 \\
\hline
\end{tabular}

* The sodalite synthesized without template is taken to $100 \%$ crystallinity.

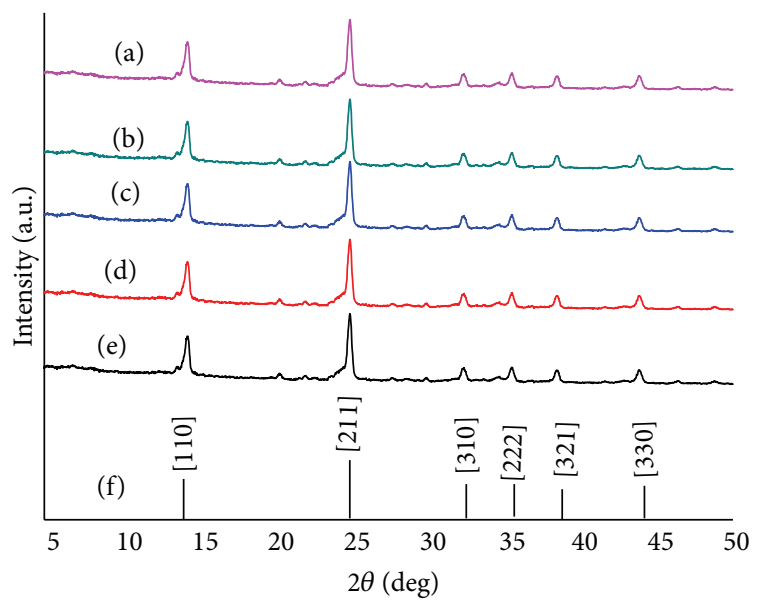

FIGURE 1: XRD patterns of synthesized samples using fumed silica as silica source, (a) sodalite without template, (b) organosilane, (c) TPA, (d) CTABr, and (e) TPA and CTABr 1:1 as templates, as well as (f) reference for sodalite (Zeolite 16:323-802, 1996).

sodalite octahydrate zeolite and confirmed by comparing the diffraction peaks at $2 \theta$ degree, 13.97, 24.938, 32.368, 35.452, 38.468, and 44.887 (Zeolite 16:323-802, 1996). These peaks correspond to the planes [110], [211], [310], [222], [321], and [330]. It can be seen from Figure 1 that all synthesized samples showed the formation of sodalite phase [19]. Table 1 shows the crystallinity and the crystallite size $(\mathrm{nm})$ of the sodalite formation using different templates. It can be seen from Figure 1 that all synthesized samples showed the formation of sodalite with different crystallinity. High crystallinity and pure sodalite have been formed without template and also by using organosilane and TPA: CTABr 1:1. However, low crystallinity of sodalite was formed when using TPA and $\mathrm{CTABr}$. In addition, some other phases were observed to exist in the sodalite sample of TPA and CTABr.

Figure 2 shows the FTIR spectra of samples synthesized using different templates. In general, the IR spectrum of each sample shows two main peaks with different sharpness. The IR peak pattern shows the IR in a typical vibration pattern for the sodalite framework [20]. IR spectra of the samples showed broad band of asymmetric stretching of Si-O-T ( $\mathrm{T}=$ Si or $\mathrm{Al}$ ) bond that was observed around $903-948 \mathrm{~cm}^{-1}$ which indicated the formation of $\mathrm{Si}-\mathrm{O}-\mathrm{Al}$ bond. The absorption band around about $690 \mathrm{~cm}^{-1}$ is due to the symmetric stretch

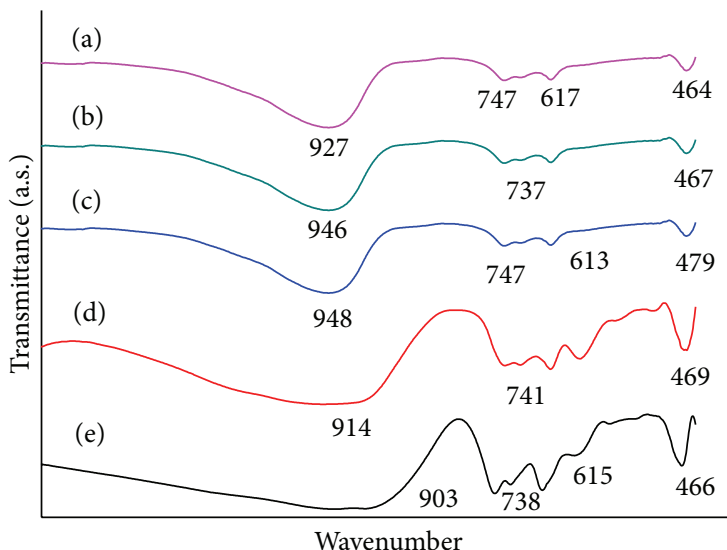

FIGURE 2: FTIR spectra of synthesized samples using fumed silica as silica source, (a) sodalite without template, (b) organosilane (c) TPA, (d) CTABr, and (e) TPA and CTABr 1:1 as template.

in the region of $660-770 \mathrm{~cm}^{-1}$ (Si-O-T). The bonds around $450-475 \mathrm{~cm}^{-1}$ show the bending vibrations of Si-O-T [14].

The surface morphology of the synthesized samples was studied by Field Emission Scanning Electron Microscopy (FESEM). The FESEM Micrograph of sodalite obtained from organosilane and a mixture of TPA : CTABr templates showed regular spherical morphology with various range nanoparticle sizes $~ 10-16 \mathrm{~nm}$ (Figures 3(a) and 3(b)). It can be observed that the sodalite obtained using a mixture of TPA: CTABr has larger particle size. Sodalite synthesized without template appears to be in the form of cubic sodalite nanocrystals in $\mu \mathrm{m}$ range size (Figure $3(\mathrm{c})$ ).

3.2. Surface Area and Pore Distribution Analysis. The samples were characterized using $\mathrm{N}_{2}$ sorption to determine their surface area and pore structure [21]. Depending mainly on the structure of solids, the adsorption of gases and vapors gives rise to I-VI types of isotherm. Figure 4 shows the isotherm and pore distribution for synthesized samples using organosilane and a mixture of TPA and CTABr as a template. Sample sodalite obtained from organosilane exhibited isotherm type IV with hysteresis loop. This type IV pattern is typical of mesoporous solids as in Figure 4(a) (i). The hysteresis loop shows H1-type with open-ended cylindrical pores with a uniform size and shape. It was proven from the pore distribution in Figure 4(b) (ii) which exhibited one narrow peak center at $c a .7 \mathrm{~nm}$. It can be suggested that the average pore size of the mesoporous sodalite obtained by organosilane was $c a .7 \mathrm{~nm}$.

On the other hand, the synthesized sample using mix template shows type VI with H2-type hysteresis loop which associated with a capillary condensation in bottle pores shape. Type VI isotherm associated with multilayers adsorption. It can be seen from the isotherm in Figure 4(a) (iii) that there were two steps with increased volume which occurred at $P / P_{0} 0.2$ and 0.6 , respectively. It can be suggested that the sodalite has two different sizes of pores as shown by the pore distribution of the sodalite sample in Figure 4(b) (iv). It shows that sample sodalite obtained by mixture of TPA and CTABr 


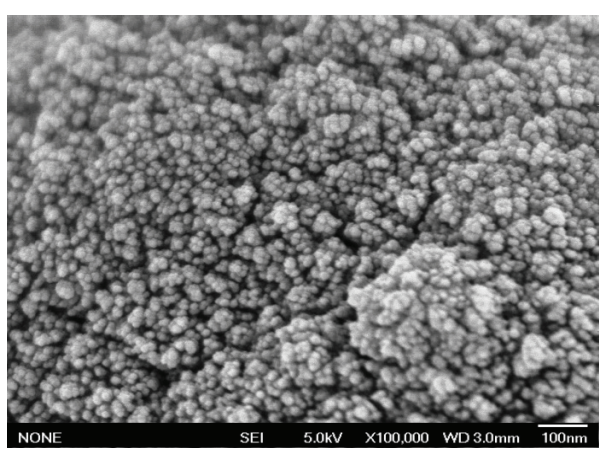

(a)

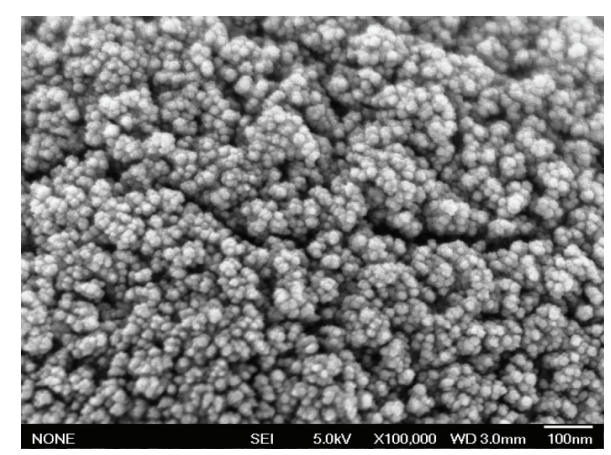

(b)

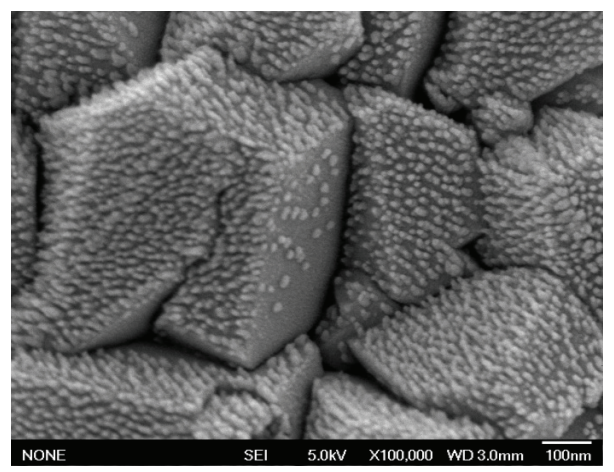

(c)

FIGURE 3: Field emission scanning electron micrographs of synthesized samples. (a) SOD using organosilane, (b) SOD using TPA and CTABr $1: 1$, and (c) SOD without template.

TABLE 2: Summarized results of $\mathrm{N}_{2}$ adsorption-desorption for synthesized samples using different templates.

\begin{tabular}{lccccc}
\hline Sample & Template & $S_{\mathrm{BET}} \mathrm{m}^{2} \mathrm{~g}^{-1}($ single point $)$ & $P_{V}^{\mathrm{b}}\left(\mathrm{mL} \mathrm{g}^{-1}\right)$ & $\begin{array}{c}\text { External surface } \\
\mathrm{area} \mathrm{m}^{2} \mathrm{~g}^{-1}\end{array}$ & $\begin{array}{c}\text { Average pore } \\
\text { distribution }(\mathrm{nm})\end{array}$ \\
\hline SOD & - & 11 & 0.002128 & 1 & - \\
SOD-OS & Organosilane & 151 & 0.3247 & 142 & 7 \\
SOD-TP & TPA & 65 & NA & NA & - \\
SOD-CT & CTABr & 41 & NA & NA & - \\
SOD-TC & TPA and CTAB 1:1 & 266 & 0.37475 & 306 & $22 \& 47$ \\
\hline
\end{tabular}

${ }^{\mathrm{b}}$ Total pore volume obtained at $P / P_{0}=0.99$.

$\mathrm{NA}=$ not measurement.

has average pore size at $c a .22 \mathrm{~nm}$ and $47 \mathrm{~nm}$ due to the effect of different size of templates.

Table 2 summarizes the BET results for synthesized samples using different templates used in this study. The higher specific surface area and larger pore volume were attributed to the presence of highly mesoporous structures in the synthesized samples using organosilane and mixture of TPA and CTABr as templates. Samples synthesized without template and synthesized by using only TPA or CTABr produced sodalite with low surface area.

3.3. Effect of Templates. The results from Section 3.2 show that sodalite obtained from organosilane and mixture of TPA and CTABr gave mesoporous sodalite. However, both samples exhibited different isotherms and pore distribution. It indicated that different types of templates directed the formation of different pore structure of mesoporous sodalite. Organosilane as a template can well incorporate into aluminosilicate sphere during the crystallization of zeolite concurrently mesoporosity is formed because of the organic tail of this template. The key for the design was amphiphilic surfactant molecules that contained a hydrolysable methoxysilyl moiety, a zeolite structure directing group (quaternary ammonium), and a hydrophobic alkyl chain moiety. It was expected that such amphiphilic organosilane could strongly interact with growing crystal domains through the formation of covalent bonds with other $\mathrm{SiO}_{2}$ and $\mathrm{Al}_{2} \mathrm{O}_{3}$ sources using the methoxysilyl moiety.

In this work, a new one-step synthesis method of micro-/ mesoporous material by adopting the dual templates consisting of mixing the silica source and a zeolite structure directing agent cationic surfactant cetyltrimethylammonium 


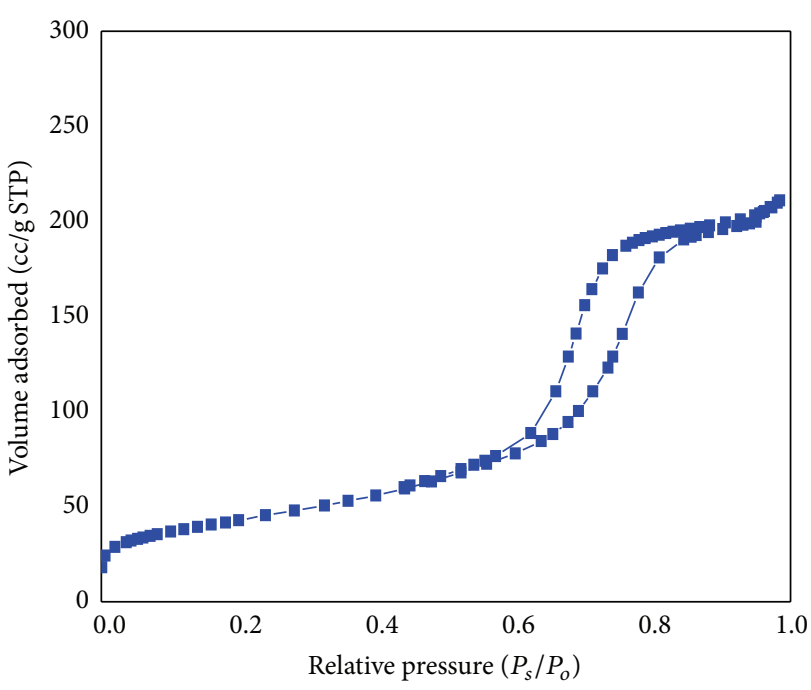

(i) $\mathrm{N}_{2}$ sorption isotherms

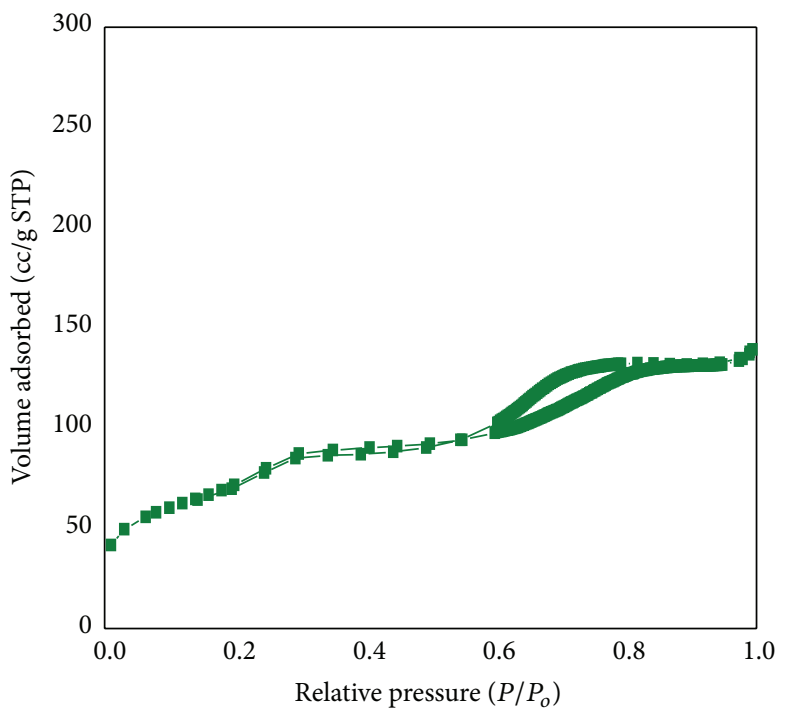

(iii) $\mathrm{N}_{2}$ sorption isotherms

(a)

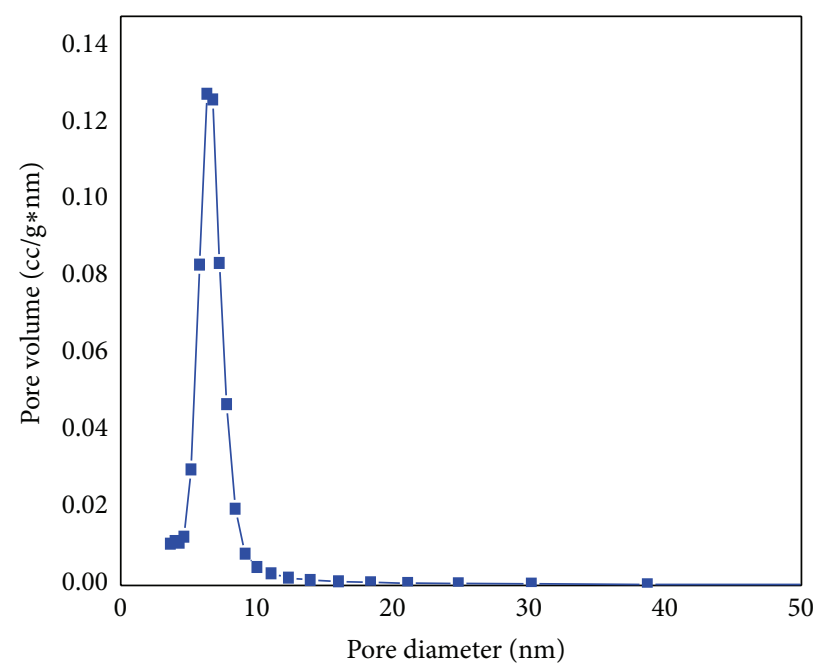

(ii) Pore size distribution

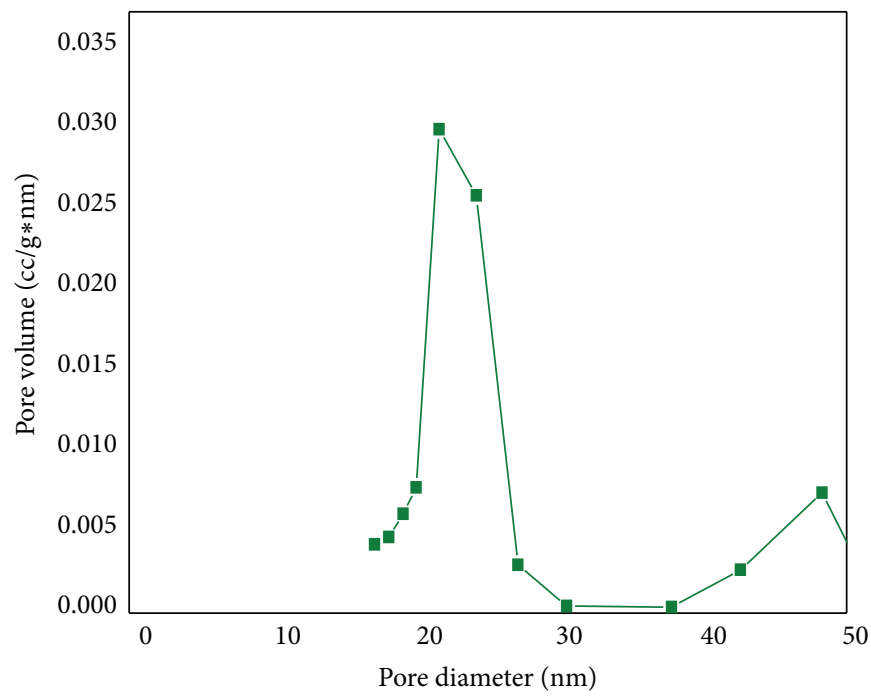

(iv) Pore size distribution

(b)

FIGURE 4: (a) $\mathrm{N}_{2}$ sorption isotherms: (i) SOD-OS and (iii) SOD-TC. (b) Pore size distribution: (ii) SOD-OS and (iv) SOD-TC.

bromide (CTABr) and mesotemplate tetrapropyl ammonium hydroxide (TPA) in one reaction vessel was reported. The main idea behind this approach is to have an in situ formation of zeolitic particles that organise around the mesotemplate micelles. Two types of mesopores are present throughout the whole zeolite crystals and form a highly interpenetrating and uniform porous network. They can form mixed micelles and induce mesoporous materials with extremely large BET surface area. In fact, condensation between the primary aluminosilicates units (zeolite seeds) and TPA micelles forms mesoporous zeolite aggregates, and then the zeolite aggregates stack between the aggregates and the $\mathrm{CTABr}$ micelles leads to the synchronous formation of CTABr micelles. Further assembly, crystallization, and growth of the aggregates during hydrothermal treatment lead to the formation of mesoporosity. This strategy provides a new convenient method to prepare the micro-/mesoporous materials.

\section{Conclusion}

Synthesis of mesoporous sodalite was investigated in this study using several templates. We have found that a mixture of TPA and CTABr with mole ratio of $1: 1$ as a template beside organosilane has potential for formation of mesoporosity in sodalite. Mesoporous sodalite using organosilane and mixture of TPA: CTABr has been synthesized successfully containing mesoporous-microporous hierarchical structure. The synthesized samples showed different isotherm and pore distribution due to difference in their structure directing template. Both of the synthesized samples exhibited higher 
surface area and larger pore volume than microporous sodalite. It can be suggested that sodalite with mesoporosity has been formed.

\section{Conflict of Interests}

The authors declare that there is no conflict of interests regarding the publication of this paper.

\section{Acknowledgment}

The authors would like to thank the Universiti Teknologi Malaysia for their financial funding through GUP Grant Vote $06 \mathrm{H} 70$.

\section{References}

[1] M. Zaarour, B. Dong, I. Naydenova, R. Retoux, and S. Mintova, "Progress in zeolite synthesis promotes advanced applications," Microporous and Mesoporous Materials, vol. 189, pp. 11-21, 2014.

[2] N. Pal and A. Bhaumik, "Soft templating strategies for the synthesis of mesoporous materials: inorganic, organic-inorganic hybrid and purely organic solids," Advances in Colloid and Interface Science, vol. 189-190, pp. 21-41, 2013.

[3] Z. Jin, X. Wang, and X. Cui, "Synthesis and morphological investigation of ordered SBA-15-type mesoporous silica with an amphiphilic triblock copolymer template under various conditions," Colloids and Surfaces A: Physicochemical and Engineering Aspects, vol. 316, no. 1-3, pp. 27-36, 2008.

[4] M. M. Huang, S. Kaliaguine, M. Muscas, and A. Auroux, "Microcalorimetric characterization of the basicity in alkaliexchanged X zeolites," Journal of Catalysis, vol. 157, no. 1, pp. 266-269, 1995.

[5] Z. Qin, B. Shen, Z. Yu et al., "A defect-based strategy for the preparation of mesoporous zeolite $\mathrm{Y}$ for high-performance catalytic cracking," Journal of Catalysis, vol. 298, pp. 102-111, 2013.

[6] X. Liu, H. He, Y. Wang, S. Zhu, and X. Piao, "Transesterification of soybean oil to biodiesel using $\mathrm{CaO}$ as a solid base catalyst," Fuel, vol. 87, no. 2, pp. 216-221, 2008.

[7] A. Petushkov, S. Yoon, and S. C. Larsen, "Synthesis of hierarchical nanocrystalline ZSM-5 with controlled particle size and mesoporosity," Microporous and Mesoporous Materials, vol. 137, no. 1-3, pp. 92-100, 2011.

[8] L. Wang, C. Yin, Z. Shan, S. Liu, Y. Du, and F.-S. Xiao, "Breadtemplate synthesis of hierarchical mesoporous ZSM-5 zeolite with hydrothermally stable mesoporosity," Colloids and Surfaces A: Physicochemical and Engineering Aspects, vol. 340, no. 1-3, pp. 126-130, 2009.

[9] M. L. Gonçalves, L. D. Dimitrov, M. H. Jordão, M. Wallau, and E. A. Urquieta-González, "Synthesis of mesoporous ZSM-5 by crystallisation of aged gels in the presence of cetyltrimethylammonium cations," Catalysis Today, vol. 133-135, no. 1-4, pp. 6979, 2008.

[10] G. V. Shanbhag, M. Choi, J. Kim, and R. Ryoo, "Mesoporous sodalite: a novel, stable solid catalyst for base-catalyzed organic transformations," Journal of Catalysis, vol. 264, no. 1, pp. 88-92, 2009.

[11] M. Reichinger, W. Schmidt, V. V. Narkhede, W. Zhang, H. Gies, and W. Grünert, "Ordered mesoporous materials with
MFI structured microporous walls-synthesis and proof of wall microporosity," Microporous and Mesoporous Materials, vol. 164, pp. 21-31, 2012.

[12] G. Harding, "X-ray diffraction imaging-a multi-generational perspective," Applied Radiation and Isotopes, vol. 67, no. 2, pp. 287-295, 2009.

[13] A. K. Ladavos, A. P. Katsoulidis, A. Iosifidis, K. S. Triantafyllidis, T. J. Pinnavaia, and P. J. Pomonis, "The BET equation, the inflection points of $\mathrm{N}_{2}$ adsorption isotherms and the estimation of specific surface area of porous solids," Microporous and Mesoporous Materials, vol. 151, pp. 126-133, 2012.

[14] J. Yao, L. Zhang, and H. Wang, "Synthesis of nanocrystalline sodalite with organic additives," Materials Letters, vol. 62, no. 24, pp. 4028-4030, 2008.

[15] R. Kimura, D. T. Nghia, J. Wakabayashi, S. P. Elangovan, M. Ogura, and T. Okubo, "Nepheline synthesized from sodalite as diesel-soot combustion catalyst: structure property relationship study for an enhanced water tolerance," Bulletin of the Chemical Society of Japan, vol. 85, no. 4, pp. 527-532, 2012.

[16] S. Jaenicke, G. K. Chuah, X. H. Lin, and X. C. Hu, "Organicinorganic hybrid catalysts for acid- and base-catalyzed reactions," Microporous and Mesoporous Materials, vol. 35-36, pp. 143-153, 2000.

[17] M. Fujiwara, A. Sakamoto, K. Shiokawa, A. K. Patra, and A. Bhaumik, "Mesoporous MFI zeolite material from silicaalumina/epoxy-resin composite material and its catalytic activity," Microporous and Mesoporous Materials, vol. 142, no. 1, pp. 381-388, 2011.

[18] M. Enterría, F. Suárez-García, A. Martínez-Alonso, and J. M. D. Tascón, "Preparation of hierarchical micro-mesoporous aluminosilicate composites by simple y zeolite/MCM-48 silica assembly," Journal of Alloys and Compounds, vol. 583, pp. 60-69, 2014.

[19] K. Ebitani, K. Motokura, K. Mori, T. Mizugaki, and K. Kaneda, "Reconstructed hydrotalcite as a highly active heterogeneous base catalyst for carbon-carbon bond formations in the presence of water," The Journal of Organic Chemistry, vol. 71, no. 15, pp. 5440-5447, 2006.

[20] D. Barthomeuf, "Framework induced basicity in zeolites," Microporous and Mesoporous Materials, vol. 66, no. 1, pp. 1-14, 2003.

[21] C. Baerlocher, L. B. McCusker, and D. H. Olson, Atlas of Zeolite Framework Types, Elsevier, 2007. 

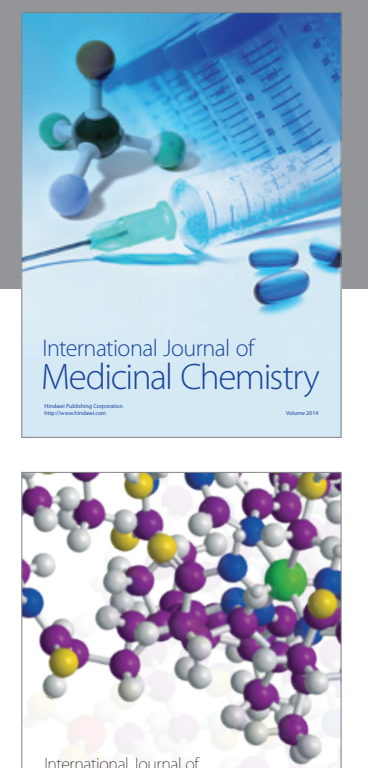

\section{Carbohydrate} Chemistry

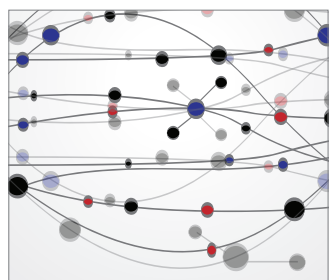

The Scientific World Journal
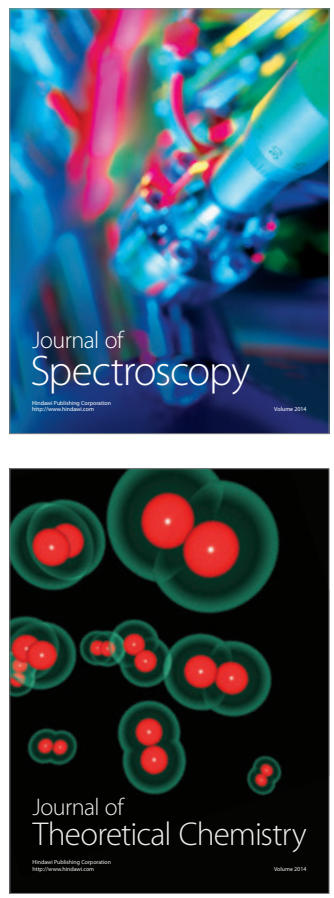
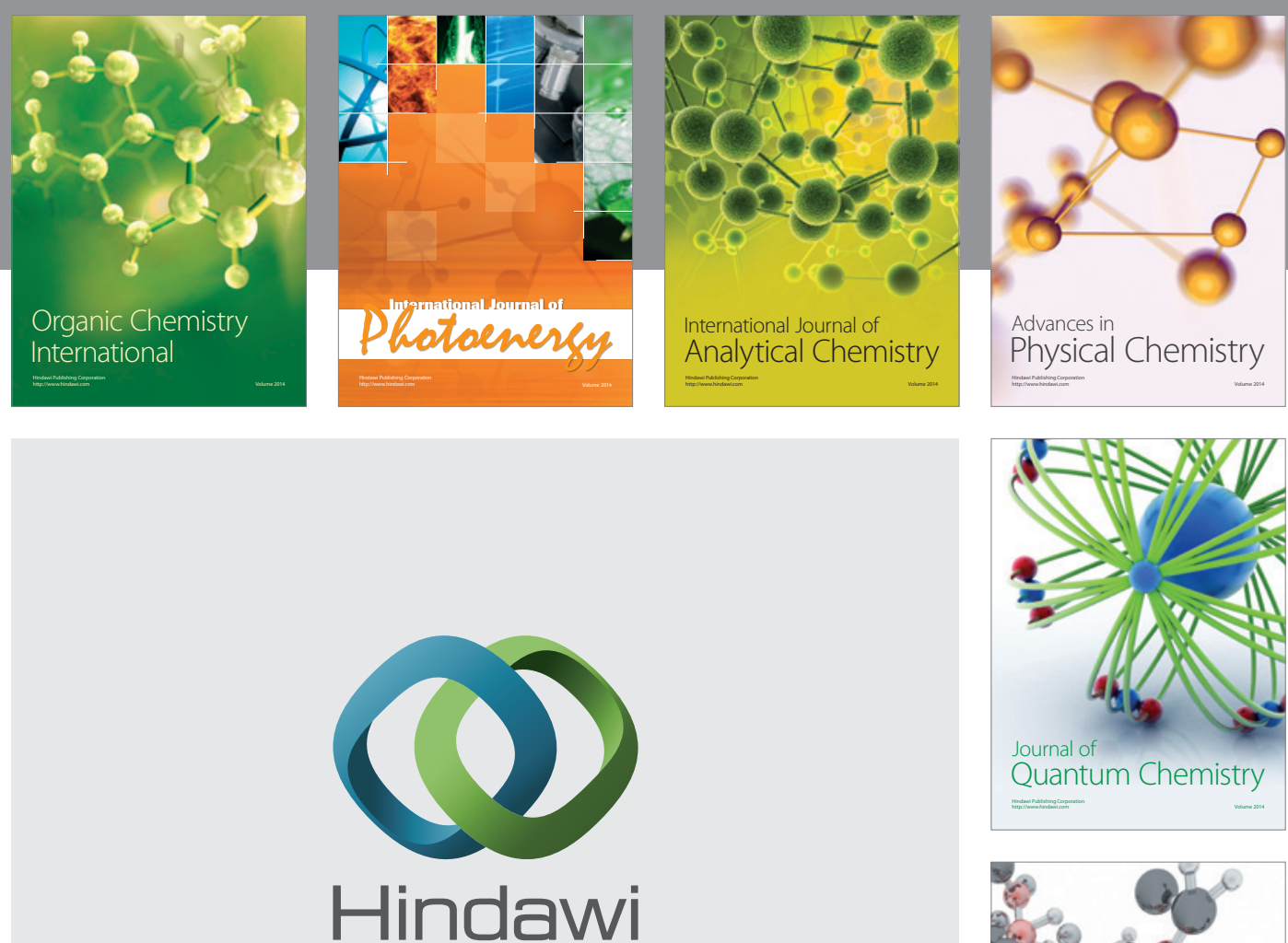

Submit your manuscripts at

http://www.hindawi.com

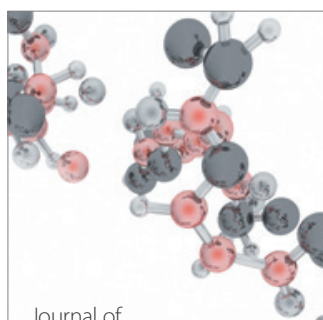

Analytical Methods

in Chemistry

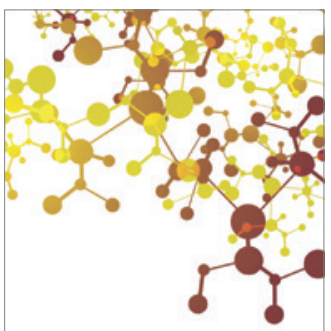

Journal of

Applied Chemistry

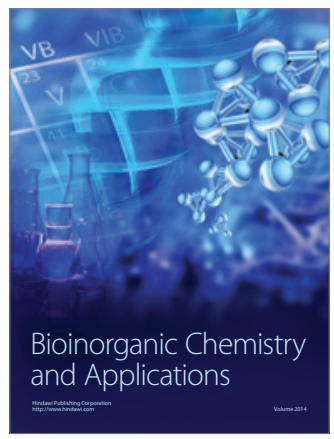

Inorganic Chemistry
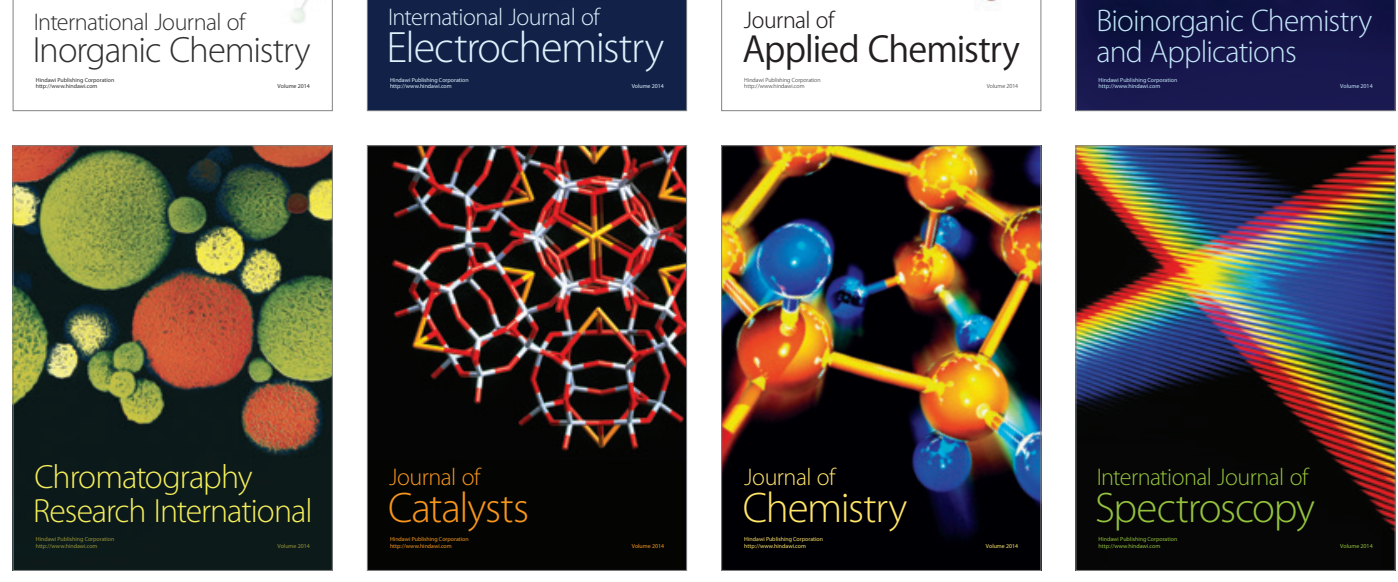